\title{
Role of shear wave sono-elastography (SWE) in characterization of hepatic focal lesions
}

\author{
Mahmoud Abdel-Latif*, Nehad Fouda, Osama Abdel-Gawad Shiha and Amira Ali Rizk
}

\begin{abstract}
Background: Focal liver lesions are considered a major problem during abdominal examinations. Shear wave sonoelastography (SWE) has been demonstrated to be helpful in assessment of liver fibrosis degree.

The purpose of this study was to evaluate the role of SWE in characterization of benign and malignant hepatic focal lesions.

Results: Seventy-five (75) patients with variable focal liver lesions (52 malignant and 23 benign) were analyzed by SWE. The stiffness values of surrounding hepatic parenchyma were also measured as a reference for readings of the focal lesion stiffness values. Final diagnosis was achieved by core needle biopsy (in 1 benign and 38 malignant cases) and contrast enhanced CT and MRI (in all cases).

Cholangiocarcinoma (CCC) was the stiffest malignant lesion with median stiffness value $(35.9 \mathrm{kPa})$. Focal nodular hyperplasia $(\mathrm{FNH})$ was the stiffest benign lesion $(26.7 \mathrm{kPa})$.

The median stiffness value of malignant focal lesions $(20.22 \mathrm{kPa}$ ) was significantly higher than that of benign focal lesions $(10.68 \mathrm{kPa})(P$ value $<0.001)$.

ROC curve of SWE median stiffness values for differentiation of benign from malignant hepatic focal lesions had AUC $=0.834$, and using cut of value $14.165 \mathrm{kPa}$, yielding $98.1 \%$ sensitivity, $78.3 \%$ specificity, and $92 \%$ accuracy.

Conclusion: SWE has high accuracy in differentiating benign form malignant liver focal lesions with promising results in individual characterization of some malignant (HCC and CCC) and benign hepatic focal lesion (FNH from other benign lesions).
\end{abstract}

Keywords: Hepatic focal lesions, Benign, Malignant, Shear wave elastography, Characterization, Stiffness value

\section{Background}

Focal liver lesions (FLLs) are considered a major problem during abdominal examinations. Liver cancer represents the second leading cause of mortality in men and the sixth cause in women worldwide [1]. FLLs are classified as benign or malignant. Benign hepatic lesions can be either solid or cystic, within these types; the subtypes include hemangioma (the most common), hepatic adenoma, focal nodular hyperplasia, focal fatty change, bile duct cysts, and hydatid cysts [2, 3]. Malignant hepatic

* Correspondence: drlatif72@yahoo.com

Department of Radio Diagnosis, Mansoura University Hospital (MUH), Mansoura, Egypt

\section{Springer Open}

focal lesions can be either primary or secondary (metastases). The commonest primary malignant liver neoplasm is hepatocellular carcinoma (HCC) and the second most common neoplasm is cholangiocarcinoma. There are other rare liver neoplasms as angiosarcomas and hepatoblastomas [4].

Several diagnostic imaging modalities can be used to detect and characterize FLLs as ultrasound, color Doppler, magnetic resonance imaging (MRI), computed tomography $(\mathrm{CT})$, and positron emission tomography (PET). More invasive techniques include angiography (seldom used) and percutaneous biopsy [5]. 
Ultrasound is a first-line modality for examination of the liver because it is low in cost, convenient to use, and does not expose the patient to radiation. In CT examination, intravenous iodinated contrast media are routinely used that improve detection of FLLs. CT limitations are exposure to a high radiation dose and contrast media are contraindicated in patients with a history of anaphylaxis and renal failure. MRI in comparison to CT lacks exposure to ionizing radiation and contrast agents of MRI can be used in patients who have allergies to iodinated contrast agents. The main drawbacks of MRI include high cost and the long examination time [6].

Core needle liver biopsy has been considered the gold standard tool for differentiating malignant from benign lesions. However, it is an invasive procedure, and may have life-threatening complications as pain, risks of morbidity and mortality and also, biopsy diagnostic value is limited by sampling variability [7-10].

Ultrasound elastography is a new imaging technique that allows a noninvasive estimation and imaging of tissue elasticity distribution within biological tissues using conventional real-time ultrasound equipment with modified software [11].

Shear wave sono-elastography (SWE) is a novel elastographic technique that has been suspected to be an alternative, easy, rapid, and noninvasive technique that is increasingly being used to assess liver elasticity [12]. It gives a local assessment at point of interest of an organ in kilopascals $(\mathrm{kPa})$. The major advantages of SWE are the reproducibility, operator independency, higher spatial resolution, and the ability to establish a quantitative evaluation of stiffness values without manual compression artifacts [13]. SWE technique generates shear waves at a focal point in the tissue, where the velocity of the wave provides an estimate of tissue stiffness $[14,15]$.

SWE has been demonstrated to be helpful in assessment of liver fibrosis degree [16] and may be used as an adjunct to conventional ultrasound in differentiation and characterization of hepatic focal lesions $[12,17]$.

\section{Aim of the work}

The aim of this study is to evaluate the role of shear wave sono-elastography (SWE) in characterization of benign and malignant hepatic focal lesions.

\section{Methods}

This prospective study was carried out during the period from March 2017 to March 2019. It included patients with single or multiple hepatic focal lesions greater than $1 \mathrm{~cm}$ in diameter, diagnosed by any of different imaging modalities, who agreed to join the study according to the ethical considerations. Patients with focal lesion size smaller than the size of the smallest sampling box $(1 \times$ $1 \mathrm{~cm}$ ), patients who were unable to hold their breath as required, those with previous interference to hepatic focal lesions, pregnant, obese, and those patients with bad general condition were excluded.

The study included ninety-one (91) cases with 114 variable hepatic focal lesions. Patients with multiple hepatic focal lesions, the largest or the most conspicuous one was chosen only as a representative lesion in compliance with the study of Qiang et al. [18]. Sixteen (16) cases were excluded from the statistical analysis because of failure of SWE acquisitions (6 cases of left liver lobe focal lesions and cases of right liver lobe focal lesions more than $6 \mathrm{~cm}$ in depth from skin $(N=10)$ in compliance with the Gerber et al. study) [19].

So the current study final statistical analysis cases included 75 patients (42 males and 33 females), their age ranged from 19 to 67 years with mean age of 50.13 years.

Patients were subjected to the following:

1. Ultrasonography: This study was done by using the ultrasound machine: LOGIQ E9 (GE Healthcare) with convex transducer (C1-6-D 3.5 MHZ). All cases were subjected to B-mode abdominal ultrasonography examination followed by shear wave elastography of the hepatic focal lesions and the surrounding liver parenchyma.

All the examinations were performed by consensus by 2 independent radiologists (M.A.L. and N.F.). They had more than 20 and 25 years' experiences in ultrasonic scanning. Both were blinded to the final pathologic results and other investigation done for the patients.

\section{B-mode abdominal ultrasonography examination}

Patient was lying in supine position. At first, a baseline B-mode liver ultrasound was performed to obtain each focal lesion criteria (location, echogenicity, maximum diameter, boundary, associated ascites, and the depth from the skin).

\section{Shear wave elastography examination technique}

Patient was lying in supine position with the right arm in maximum abduction. A liver area free of visible bile ducts or vessels was selected. The built-in ROI of the system was placed inside the lesion, and the image was displayed on a semi-transparent color map of tissue stiffness, ranging from dark blue indicating the lowest stiffness, to dark red indicating the highest stiffness.

The surrounding hepatic parenchyma stiffness values were also measured to give a direct reference for shear wave elastography readings of the focal lesion stiffness values.

The patients were asked to perform a short breath hold, to ensure that cardiac- and respiration-related tissue motion was minimum. Three consecutive shear wave elastography acquisitions were performed for the lesion and the surrounding parenchyma, then the 
average stiffness value of the three readings $(\mathrm{kPa})$ was calculated. Finally, measurements and images were recorded

2. Contrast enhanced computed tomography (CE-CT): All patients (75) were subjected to post-contrast triphasic CT study using 128 multi-detector Philips CT with the following parameters: KV, 120; MA, 200-250; slice thickness, $10 \mathrm{~mm}$; and FOV, $400 \mathrm{~mm}$ (scanning from the lung bases to the iliac crest and should include the whole liver).

After digital scout view, a pre-contrast axial scan was first obtained. Then triphasic CT scanning of the liver was performed as patients were given IV nonionic contrast of $1.5 \mathrm{mg} / \mathrm{kg}$ with overall dose of 100 $150 \mathrm{~mL}$ via a power injector at $2-3 \mathrm{~mL} / \mathrm{s}$. Then liver was scanned in arterial (after 10-30 s), portal (after 60-90 s), and equilibrium or delayed (after 2-5 min) phases.

3. Contrast enhanced magnetic resonance imaging (CE-MRI): All cases were examined by post-contrast triphasic MRI study using $1.5 \mathrm{~T}$ machine (Philips-Ingenia 1.5) with the following parameters: T1WI (TR, $500 \mathrm{~ms}$; TE, $50 \mathrm{~ms}$; slice thickness, $5 \mathrm{~mm}$; and FOV, $400 \times 300$ $\mathrm{mm}$ ). T2WI (TR, $1250 \mathrm{~ms}$; TE, $80 \mathrm{~ms}$; slice thickness, 5 $\mathrm{mm}$; and FOV, $400 \times 300 \mathrm{~mm}$. Dynamic post-contrast study (TR, $3.5 \mathrm{~ms}$; TE, $1.5 \mathrm{~ms}$; slice thickness, $2 \mathrm{~mm}$; and FOV , $400 \times 300 \mathrm{~mm}$ ) with one pre-contrast and 3 postcontrast series, after pre-contrast study, a bolus of GdDTPA in a dose of $0.2 \mathrm{mmol} / \mathrm{kg}$ was injected using an automated injector at a rate of $3-5 \mathrm{ml} / \mathrm{s}$, liver was scanned in arterial after $20-30 \mathrm{~s}$, portal after $60-65 \mathrm{~s}$, and equilibrium phase after $2-5 \mathrm{~min}$. Also, DWI (TR, $1885 \mathrm{~ms}$; TE, $62 \mathrm{~ms}$; slice thickness, $5 \mathrm{~mm}$; and FOV, 400 $\times 300 \mathrm{~mm}$ ), in-phase and out-phase T1WI (TR, $4.6 \mathrm{~ms}$; TE, $2.3-4.3 \mathrm{~ms}$; slice thickness, $5 \mathrm{~mm}$; and FOV, $400 \times$ $300 \mathrm{~mm}$ ) and heavy T2WI (TR, 10,000; TE, $260 \mathrm{~ms}$ ) were done if needed.

4. Core Needle Biopsy: Thirty-nine (39 cases, 38 malignant and 1 benign) underwent core needle biopsy of hepatic focal lesions.

An ultrasound guided liver biopsy was performed, obtaining 2-3 histological tissue samples of about 20 $\mathrm{mm}$ in length using an 18-G biopsy needle.

The final diagnosis of benign hepatic focal lesions (hemangioma, focal nodular hyperplasia, focal fatty infiltration...etc.) was made by the agreement of the three imaging techniques (US, triphasic $\mathrm{CT}$, and triphasic MRI). In case of persistent diagnostic uncertainty (in 1 case of $\mathrm{FNH}$ ), liver biopsy was done.

The diagnosis of HCC: provided there was liver cirrhosis, the guidelines of the American Association Society of Liver Disease (AASLD, 2005) was followed for diagnosis (in 14 HCC cases). In all other malignant lesions, (in 7 cases of atypical HCC, 21 metastases, 6 lymphomas, and 4 cases of cholangiocarcinoma) biopsy was taken.

All CT and MRI examinations were interpreted by a specialized radiologist (O.A.SH.) with 15 years' experience in CT and MRI liver imaging.

\section{Statistical analysis}

The data from B-mode abdominal ultrasound studies and shear wave elastography value results were transferred to statistical package for social science (SPSS) program, version 20, on Microsoft windows for statistical analysis. Quantitative data were summarized by mean and standard deviation (SD) and median (minimum-maximum). Qualitative data were summarized by frequency and percent. Receiver operator characteristic (ROC) curve was used to determine diagnostic accuracy of test. Sensitivity and specificity for certain cutoff point was selected according to highest sensitivity and specificity.

For all above mentioned statistical tests done, the threshold of significance is fixed at 5\% level ( $P$ value).

The results were considered:

- Non-significant when the probability of error is more than $5 \%(P>0.05)$

- Significant when the probability of error is less than 5\% $(P<0.05)$

- Highly significant when the probability of error is less than $0.1 \%(P<0.001)$. The smaller the $P$ value obtained, the more significant are the results.

\section{Results}

The final number included 75 liver focal lesions (42 males and 33 females); their age range from 19 to 67 years with mean age of 50.13 years.

The study group is subdivided into two subgroups, malignant and benign hepatic focal lesions.

The percent distribution of the 75 focal lesions were the following: (a) 52 malignant focal lesions counting as hepatocellular carcinoma $(N=21)(28 \%)$, metastasis $(N$ $=21)\{2$ GIST, 2 bronchogenic carcinoma, 7 breast cancer, 6 colon cancer, 2 prostatic carcinoma, and 2 ovarian carcinoma\} (28\%), cholangiocarcinoma $(N=4)(5.3 \%)$, and lymphoma $(N=6)(8 \%)$. (b) 23 benign focal lesions counting as simple cyst $(N=2)(2.7 \%)$, hemangioma $(N$ = 6) (8\%), hydatid cyst $(N=3)(4 \%)$, focal nodular hyperplasia $(N=5)(6.7 \%)$, focal fat infiltration $(N=4)(5.3 \%)$, and abscess $(N=3)(4 \%)$ (Table 5$)$.

Fifty-two (52) patients (32 males and 20 females) had malignant hepatic focal lesions with mean age 52.9 years. Twenty-three (23) patients (10 males and 13 females) had benign hepatic focal lesions with mean age 43.8 years.

Malignant hepatic focal lesions (52): all cases were diagnosed by contrast enhanced CT study (CE-CT) and by 
contrast enhanced MRI study (CE-MRI), in addition, 38 cases were diagnosed by biopsy (Table 1 ).

Benign hepatic focal lesions (23): all patients were diagnosed by contrast enhanced CT study (CE-CT) and by contrast enhanced MRI (CE-MRI). One (1) case of FNH was diagnosed by biopsy (Table 1 ).

Malignant focal lesion median size was 5.30 (range from 2.90 to 12.0). Benign focal lesion median size was 6.70 (2.90-18.1) (Table 2).

Twelve (12) malignant focal lesions were associated with ascites. None of the benign focal lesions had associated ascites. The data is summarized in Table 2.

Color-coded elastogram of the 52 malignant hepatic focal lesions: 46 lesions (21 hepatocellular carcinoma, 21 metastasis, and 4 cholangiocarcinoma) showed mixed color with red foci and 6 lesions showed yellow green color (6 lymphomas) (Table 3).

Color-coded elastogram of 23 benign hepatic focal lesions: 12 lesions (6 hemangioma, 2 hydatid, and 4 focal fatty infiltration) showed faint blue color, 4 lesions showed yellow green color ( 3 abscess and 1 hydatid), 5 lesions showed mixed color with red foci (5 focal nodular hyperplasia), and 2 lesions were colorless (2 simple cyst) (Table 3).

There was statistical significant difference of color characteristics between malignant and benign hepatic focal lesions $(P$ value $<0.001)$ (Table 3$)$.

The median stiffness value of malignant focal lesions $(20.22 \mathrm{kPa})$ was significantly higher compared with that of benign focal lesions $(10.68 \mathrm{kPa})$ with $P$ value $<0.001$. The median stiffness value of the liver parenchyma in cases of malignant lesions $(7.86 \mathrm{kPa})$ was higher compared with that of the liver parenchyma in cases of benign lesions $(5.97 \mathrm{kPa})$ with a statistical significance $P$ value $=0.002$. The median lesion/parenchyma stiffness ratio of malignant focal lesions was 2.69 and the median lesion/parenchyma stiffness ratio of benign focal lesions was 1.97 with no statistical difference (Table 4).
Regarding the benign focal lesions (Figs. 1, 2, and 3): focal nodular hyperplasia was the stiffest with median stiffness value was $26.7 \mathrm{kPa}$ and the surrounding liver parenchyma median stiffness value was 6.64 with significant $P$ value $=(0.009)$, abscess median stiffness value was 12.67 and the surrounding liver parenchymal stiffness value was 5.97 with relative significant $P$ value $=(0.05)$, hemangioma median stiffness value was 10.5 and the surrounding liver parenchyma median stiffness value was 5.84 with significant $P$ value $\leq 0.004$, focal fatty infiltration median stiffness value was 10.3 and the surrounding liver parenchyma median stiffness value was 5.57 with significant $P$ value $=(0.021)$, hydatid cyst median stiffness value was 8.79 and the surrounding liver parenchyma median stiffness value was 5.77 with relative significant $P$ value $=$ (0.05), and finally simple cyst did not exhibit any stiffness value (Table 5).

As regard the malignant focal lesions (Figs. 4, 5, 6, and 7): cholangiocarcinoma was the stiffest with median stiffness value was 35.9 and the surrounding liver parenchyma median stiffness value was 7.9 with significant statistical difference $P$ value $=0.021$, metastasis median stiffness value was 25.5 and the surrounding parenchyma median stiffness value was 5.7 with significant $P$ value $\leq 0.001$, hepatocellular carcinoma median stiffness value was 17.6 and the surrounding liver parenchyma median stiffness value was 13.2 with significant $P$ value $\leq 0.001$, and finally lymphoma median stiffness value was 14.5 and the surrounding liver parenchymal stiffness value was 5.8 with significant $(P$ value $=0.004)($ Table 5$)$.

Receiver operating characteristic (ROC) curve for the diagnostic accuracy of SWE median stiffness values for differentiation of benign from malignant hepatic focal lesions had AUC $=0.834$, and using cutoff value 14.165 $\mathrm{kPa}$, yielding $98.1 \%$ sensitivity, $78.3 \%$ specificity, and $92 \%$ accuracy (Table 6).

Table 1 Diagnosis methods among the studied groups

\begin{tabular}{|c|c|c|c|}
\hline Diagnosis methods & $\begin{array}{l}\text { Total } \\
(N=75)\end{array}$ & $\begin{array}{l}\text { Malignant hepatic focal lesions } \\
N=52\end{array}$ & $\begin{array}{l}\text { Benign hepatic focal lesions } \\
N=23\end{array}$ \\
\hline \multicolumn{4}{|l|}{ Pathology (biopsy) } \\
\hline Yes & 39 (52\%) & 38 (73.1\%) & $1(4.3 \%)$ \\
\hline No & $36(48 \%)$ & $14(26.9 \%)$ & 22 (95.7\%) \\
\hline \multicolumn{4}{|l|}{ CE-CT } \\
\hline Yes & 75 (100\%) & $52(100 \%)$ & $23(100 \%)$ \\
\hline No & $0(0.0 \%)$ & $0(0 \%)$ & $0(0 \%)$ \\
\hline \multicolumn{4}{|c|}{ CE-MRI } \\
\hline Yes & $75(0 \%)$ & 52 (100\%) & $23(100 \%)$ \\
\hline No & $0(0 \%)$ & $0(0 \%)$ & $0(0 \%)$ \\
\hline
\end{tabular}


Table 2 Lesion characteristics among the studied groups

\begin{tabular}{llll}
\hline Lesion characteristics & $\begin{array}{l}\text { Total } \\
(N=75)\end{array}$ & $\begin{array}{l}\text { Malignant hepatic focal lesions } \\
N=52\end{array}$ & $\begin{array}{l}\text { Benign hepatic focal lesions } \\
N=23\end{array}$ \\
\hline $\begin{array}{l}\text { Lesion size } \\
\text { Median (min-max) }\end{array}$ & $6.7(2.9-18.10)$ & $5.30(2.90-12.0)$ & $6.70(2.90-18.1)$ \\
$\begin{array}{l}\text { Lesion boundary } \\
\text { Well defined }\end{array}$ & $56(74.7 \%)$ & $39(75 \%)$ & $17(73.9 \%)$ \\
III defined & $19(25.3 \%)$ & $13(25 \%)$ & $6(26.1 \%)$ \\
Lesion echogenicity & & & \\
Isoechoic & $9(12 \%)$ & $9(17.3 \%)$ & $1(0 \%)$ \\
Heterogeneous & $11(14.7 \%)$ & $10(19.3 \%)$ & $1(4.3 \%)$ \\
Hyperechoic & $27(36 \%)$ & $18(34.6 \%)$ & $9(39.1 \%)$ \\
Hypoechoic & $24(32 \%)$ & $15(28.8 \%)$ & $9(39.1 \%)$ \\
Anechoic & $4(5.3 \%)$ & $0(0 \%)$ & $4(17.4 \%)$ \\
Ascites & $12(16 \%)$ & $12(23.1 \%)$ & $0(0 \%)$
\end{tabular}

\section{Discussion}

Only few pilot studies have evaluated the recent diagnostic imaging system (SWE) for stiffness investigation of focal liver lesions [19].

This study included 75 patients of variable hepatic focal lesions (42 males and 33 females), their age ranged from 19 to 67 years with mean age of 50.13 years. All cases were evaluated by means of B-mode abdominal ultrasound and shear wave sono-elastography, and finally diagnosed by core needle biopsy (39 cases), CE-CT, and CE-MRI (75 cases).

In the current study, the median size of benign focal lesions was $6.7 \mathrm{~cm}$ and of malignant focal lesions was $5.3 \mathrm{~cm}$. There was no statistical significance between the lesion size and its nature whether benign or malignant and in turn its stiffness in $\mathrm{kPa}$. This matches with Guibal et al. [17] and Choong et al. [20] who stated that there was no statistical correlation observed between the size of lesions and lesion stiffness value.
Regarding the color-coded elastogram, 46 malignant lesions $(88.5 \%)$ had mixed color with red foci, while only the 5 benign FNH cases (21.7\%) had red foci. There was a statistically significant difference between benign and malignant focal lesions as regard the color-coded elastogram with $P$ value $<0.001$, and this matches with the study of Guibal et al. [17] and Park et al. [21] who stated that in the technique setting, dark blue color is indicative of the lowest stiffness and dark red is indicative of the highest stiffness.

Among the benign focal lesions, focal nodular hyperplasia was the stiffest with median stiffness value $(26.7 \mathrm{kPa})$.

The median stiffness value of $\mathrm{FNH}$ was $(26.7 \mathrm{kPa})$, while that of hemangioma was $(10.5 \mathrm{kPa})$. These results are in agreement with Guibal et al. [17] who reported that SWE mean stiffness value was for FNH $33 \pm 14 \mathrm{kPa}$, and for the hemangiomas $13.8 \pm 5.5$, also with Park et al. [21] study results that included that the mean stiffness value for hemangiomas $12.91 \pm 9.42$ and for $\mathrm{FNH}$

Table 3 SWE color characteristics of benign and malignant hepatic focal lesions

\begin{tabular}{llll}
\hline Color & $\begin{array}{l}\text { Total } \\
(N=75)\end{array}$ & $\begin{array}{l}\text { Malignant hepatic focal lesions } \\
N=52\end{array}$ & $\begin{array}{l}\text { Benign hepatic focal lesions } \\
N=23\end{array}$ \\
\hline $\begin{array}{l}\text { Focal lesions } \\
\text { Yellow green }\end{array}$ & $10(13.3 \%)$ & $6(11.5 \%)$ & $4(17.4 \%)$ \\
Faint blue & $12(16 \%)$ & - & $12(52.2 \%)$ \\
Mixed with red foci & $51(68 \%)$ & $46(88.5 \%)$ & $5(21.7 \%)$ \\
Colorless & $2(2.7 \%)$ & - & $2(8.7 \%)$ \\
Parenchymal & & & - \\
Yellow green & $8(10.7 \%)$ & $8(15.4 \%)$ & - \\
Faint blue & $12(16 \%)$ & $12(23.1 \%)$ & $23(100 \%)$ \\
Dark blue & $50(66.7 \%)$ & $27(51.9 \%)$ & - \\
Mixed & $5(6.7 \%)$ & $5(9.6 \%)$ & $0.001^{*}$ \\
\hline
\end{tabular}


Table 4 Median stiffness value of benign and malignant lesions, the liver parenchyma and median lesion/parenchymal stiffness ratio

\begin{tabular}{|c|c|c|c|}
\hline Variables & $\begin{array}{l}\text { Malignant hepatic focal lesions } \\
N=52\end{array}$ & $\begin{array}{l}\text { Benign hepatic focal lesions } \\
N=23\end{array}$ & $z_{p}$ value \\
\hline \multicolumn{4}{|l|}{ Focal lesion } \\
\hline Median (min-max) & $20.22(14.04-37.51)$ & $10.68(0.0-27.76)$ & $<0.001^{*}$ \\
\hline \multicolumn{4}{|l|}{ Parenchymal } \\
\hline Median (min-max) & $7.86(4.48-18.20)$ & $5.97(4.38-7.08)$ & $0.002^{*}$ \\
\hline \multicolumn{4}{|c|}{ Lesion/parenchymal ratio } \\
\hline Median (min-max) & $2.69(0.83-5.50)$ & $1.97(0.0-4.82)$ & 0.288 \\
\hline
\end{tabular}

$27.02 \pm 4.14$, while these results do not cope with Gerber et al. [19] who concluded that there was no significant difference could be observed in elasticity values between the different benign FLLs as hemangioma median stiffness value was 16.35 (5.4-71.9) $\mathrm{kPa}$ and FNH median stiffness value was $16.55(2.1-69.7) \mathrm{kPa}$.

These studies of Guibal et al. [17], Qiang et al. [18], Gerber et al. [19], and Park et al. [21] described that hemangioma had elevated stiffness value in comparison with the surrounding hepatic parenchyma as in Park et al. study [21] hemangioma mean stiffness value was $12.91 \pm 9.42$, while parenchymal mean stiffness value was $5.5 \pm 2.8$, as well as in Gerber et al study [19] hemangioma median stiffness value was $16.35 \mathrm{kPa}$, while parenchymal median stiffness value was $8.5 \mathrm{kPa}$, and the results of the current study had similar observations as the median stiffness value of hemangioma was $10.5 \mathrm{kPa}$, the surrounding hepatic parenchymal median stiffness value was $5.84 \mathrm{kPa}$ with statistically significant $P$ value $\leq 0.004$.

Kim et al. [22] explained these results by that hemangiomas histologically composed of large blood-filled endothelial-lined spaces separated by fibrous septa, vascular thrombi likely responsible for the high stiffness values.

In the current study, abscess ( 3 cases) showed elevated stiffness value as median stiffness value was $12.67 \mathrm{kPa}$, and the surrounding liver parenchyma median stiffness value was 5.97, and this is in agreement with Park et al. [21] as abscess (3 cases) mean stiffness value was 22.13 \pm 5.14 and the surrounding liver parenchyma mean stiffness value was $5.77 \pm 1.25$.

Guibal et al. [17] and Park et al. [21] found that FNH include components significantly higher than other benign hepatic lesions in stiffness. Yu and Wilson [23] added that these elevations in stiffness likely matched to fibrous septations, which results due to central scar formation, and this copes with the results of the current study as FNH was the stiffest benign lesion.

Park et al. [21] fond that SWE mean stiffness values for focal fatty sparing $15.15 \pm 11.38$, for hematomas $31.05 \pm 1.34$, and for fibrosis 6.5, Gerber et al. [19] study also included 1 case of adenoma with median stiffness value 8.9, and Guibal et al. [17] mentioned that mean SWE values for focal fatty sparing $6.6 \pm$ 0.3 , for scars $53.7 \pm 4.7$, and for adenomas $9.4 \pm 4.3$. Guibal et al. [17] explained that adenoma stiffness values were elevated compared with surrounding parenchyma as adenoma are composed of large hepatocytes supported by a weak framework of collagen and they are deficient in biliary canaliculi. Unfortunately, this current study did not include any cases of these categories.

Among the malignant focal lesions: cholangiocarcinoma was the stiffest with median stiffness value $(35.9 \mathrm{kPa})$.

In the current study, the stiffest lesion of all types of focal lesions (benign and malignant) was cholangiocarcinomas $(35.9 \mathrm{kPa})$ and showed more stiffness values comparing with other malignant focal lesions, and this matches with Guibal et al. [17] and Gerber et al. [19] who reported that cholangiocarcinomas were the stiffest malignant FLLs.

Sirica et al. [24] and Okamoto et al. [25] explained these results by the fact that cholangiocarcinoma in histology has a considerable fibrotic component, which is also a significant portion of their malignant progression. Heide et al. [26] added that this fibrotic component is likely resulting in the high stiffness present in cholangiocarcinoma.

Guibal et al. [17] stated that none of the cholangiocarcinomas $(56.9 \pm 25.6)$ exhibited a stiffness value like the FNHs $(33 \pm 14.7)$ and this copes with the current study results as regard cholangiocarcinoma median stiffness value $(35.9 \mathrm{kPa})$ and FNH $(26.7 \mathrm{kPa})$.

The median stiffness value of HCC $(17.6 \mathrm{kPa})$ was lower than that of metastasis $(25.5 \mathrm{kPa})$ and cholangiocarcinoma $(35.9 \mathrm{kPa})$ and was higher than the median stiffness value of all benign hepatic lesions $(10.68 \mathrm{kPa})$ and lower than the stiffness value of FNH (26.7), and this is in agreement with Guibal et al. [17], Kim et al. [22], and Frulio et al. [27] who reported that generally hepatocellular carcinoma was harder than all benign focal lesions but softer than benign focal lesions that showed high stiffness values such as focal nodular hyperplasia. 


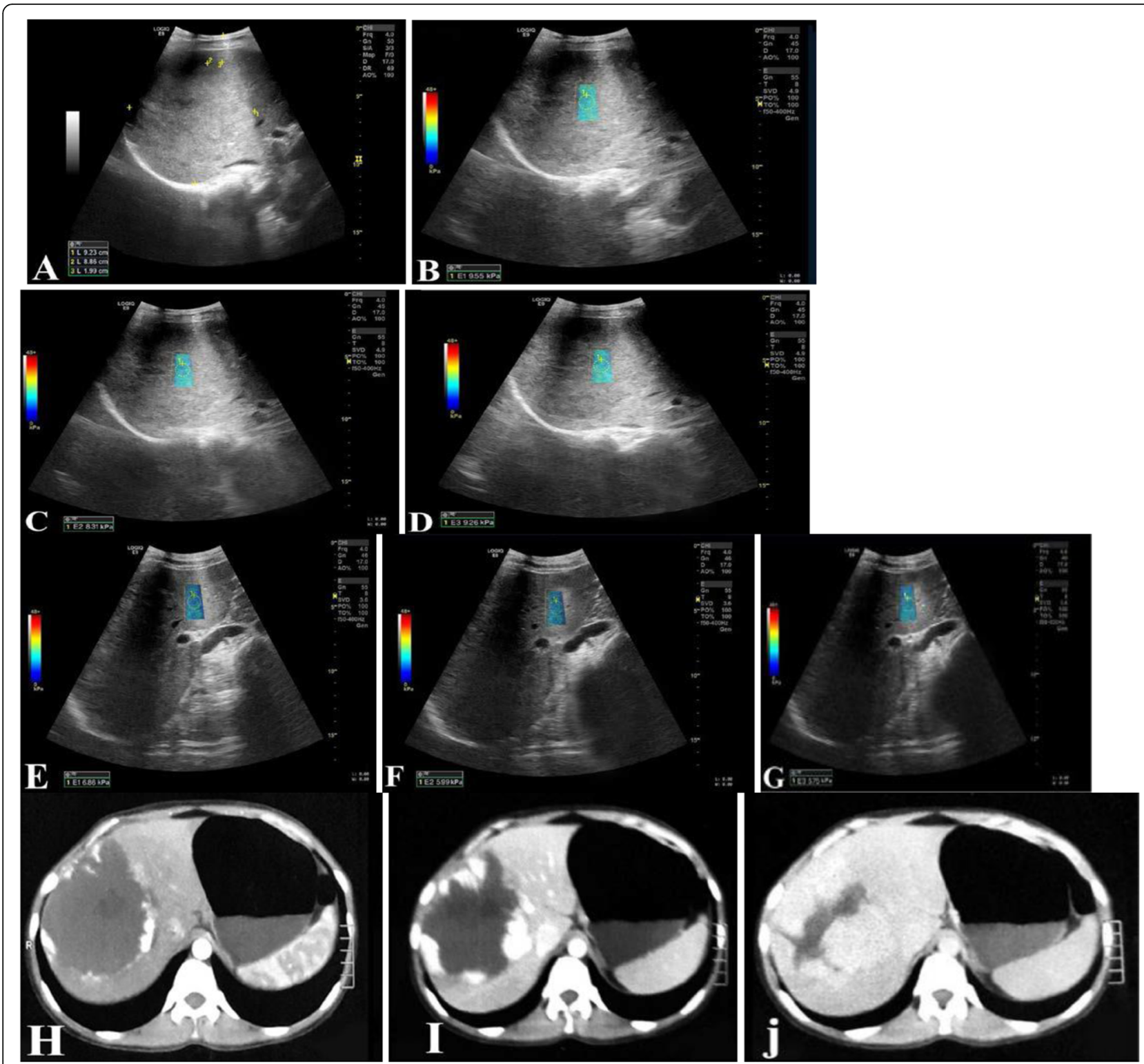

Fig. 1 Twenty-eight years old female patient presented with abdominal pain. Imaging findings: grey scale B-mode ultrasonography (a): normal sized liver with an ill-defined hyperechoic focal lesion seen in segment IV and VIII measuring $9.2 \times 8.6 \mathrm{~cm}$ with $1.9 \mathrm{~cm}$ depth from the skin. Colorcoded shear wave sono-elastography: the lesion showed faint blue color $(\mathbf{b}, \mathbf{c}, \mathbf{d})$, while the liver parenchyma showed dark blue color (e, $\mathbf{f}, \mathbf{g})$. Shear wave sono-elastography stiffness value of the focal lesion: $\mathrm{E} 1=9.55 \mathrm{kPa}(\mathbf{b}), \mathrm{E} 2=8.31 \mathrm{kPa}(\mathbf{c})$, and E3 $=9.26 \mathrm{kPa}$ (d). Calculated average stiffness value of the lesion $=9.04 \mathrm{kPa}$. Shear wave sono-elastography stiffness values of the parenchyma: $\mathrm{E} 1=6.86 \mathrm{kPa}(\mathbf{e}), \mathrm{E} 2=5.99 \mathrm{kPa}(\mathbf{f})$, E3 = $5.75 \mathrm{kPa}(\mathbf{g})$.Calculated average stiffness value of the parenchyma $=6.2 \mathrm{kPa}$. Lesion/parenchyma stiffness ratio $=1.57$. Axial contrast enhanced triphasic CT study (arterial (h), portal (i), and delayed (j) phases): average sized liver with a large well defined focal lesion seen in segment IV and VIII. It shows peripheral nodular enhancement in the arterial phase, progressive filling in the portal phase with persistent enhancement is seen in the delayed phase (close iris pattern). Diagnosis: Hemangioma

Guibal et al. [17] reported that SWE mean stiffness values (in $\mathrm{kPa}$ ) were for $\mathrm{HCCs} 14.86 \pm 10$, for metastasis $28.8 \pm 16$, and for cholangiocarcinomas $56.9 \pm 25.6 \mathrm{kPa}$ with the difference in tissue elasticity between cholangiocarcinoma and HCC statistically significant $(P$ 00.0004). However, Choong et al. [20] stated that the elasticity values of $\mathrm{HCC}(51.45 \pm 14.96 \mathrm{kPa})$ were statistically non-significant from the values of metastatic lesions $(49.89 \pm 13.82 \mathrm{kPa})$.

In this study, HCC ( $N=21$ cases); 2 cases of HCC showed stiffness value $(15.27,15.1)$ less than liver parenchyma (18.2, 17.8); however, 19 cases of HCC showed stiffness value more than liver parenchyma. Also, the study of Guibal et al. [17] included 25 cases of HCC; 6 


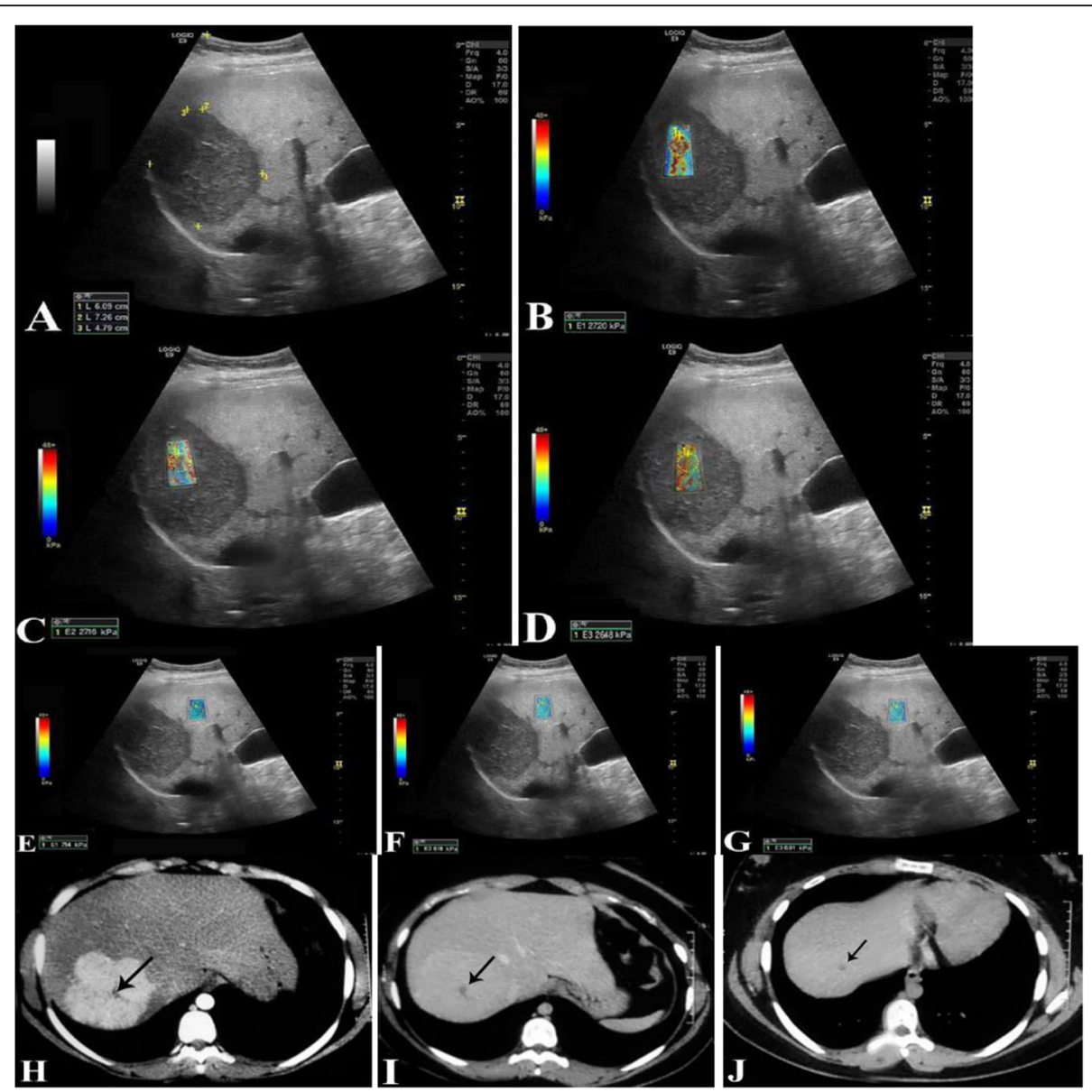

Fig. 2 Nineteen years old female patient presented with incidentally discovered hepatic focal lesion during abdominal ultrasound examination for abdominal pain. Imaging findings: grey scale B-mode ultrasonography (a): normal sized liver with a well-defined hypoechoic focal lesion seen in segment VII and VIII measuring $6 \times 7.2 \mathrm{~cm}$ with $4.7 \mathrm{~cm}$ depth from the skin. $\varpi$ Color-coded shear wave sono-elastography: the lesion showed mixed color with red foci $(\mathbf{b}, \mathbf{c}, \mathbf{d})$, while the liver parenchyma showed dark blue color $(\mathbf{e}, \mathbf{f}, \mathbf{g})$. $\boldsymbol{\omega}$ Shear wave sono-elastography stiffness values of the focal lesion: E1 $=27.20 \mathrm{kPa}(\mathbf{b}), E 2=27.16 \mathrm{kPa}(\mathbf{c})$, and E3 $=26.48 \mathrm{kPa}(\mathbf{d})$. Calculated average stiffness value of the lesion $=26.94 \mathrm{kPa}$. $\mathbf{D}$ Shear wave sono-elastography stiffness values of the parenchyma: $\mathrm{E} 1=7.14 \mathrm{kPa}(\mathbf{e}), \mathrm{E} 2=6.18 \mathrm{kPa}(\mathbf{f})$, and E3 $=6.91 \mathrm{kPa}(\mathbf{g})$. Calculated average stiffness value of the parenchyma $=6.74 \mathrm{kPa}$. $\cdot$ Lesion/parenchyma stiffness ratio $=3.99 .6$ Axial contrast enhanced triphasic CT study (arterial (h), portal (i), and delayed (j) phases): a well-defined lobulated hypervascular focal lesion is seen in segment VII and VIII with marked enhancement in the late arterial phase and evidence of a typical central scar within the lesion (black arrows). The portal phase demonstrates isoattenuation to the normal liver parenchyma. The delayed phase shows faint enhancement of the central scar. $\varpi$ Pathology: focal nodular hyperplasia. $\varpi$ Diagnosis: focal nodular hyperplasia (FNH)

cases showed stiffness value less than liver parenchyma, but 19 cases showed stiffness value more than liver parenchyma.

This is explained by Guibal et al. [17] and Gallotti et al. [28] who reported that HCCs in cirrhotic livers may exhibit a relatively softer values when compared with the stiff surrounding parenchyma. However, some cases of HCC showed stiffness value more than liver parenchyma by the fact that their patients likely had less degree of cirrhosis.

Gerber et al. [19] reported that the median stiffness of all FLLs [28.6 kPa] was significantly higher than that of the surrounding liver $[9.9 \mathrm{kPa}](P<0.0001)$, whereas the surrounding liver in patients with HCC showed the highest stiffness with $(P<0.0001)$ in comparison to the surrounding liver of further subgroups, and this matches with the current study results as the median stiffness of all FLLs $[18.37 \mathrm{kPa}]$ was significantly higher than that of the surrounding liver median stiffness value $[6.47 \mathrm{kPa}]$ $(P<0.001)$, whereas the surrounding liver in patients with HCC showed the highest median stiffness of 13.2 $\mathrm{kPa}(P<0.001)$ in comparison to the surrounding liver parenchyma of further subgroups.

Guibal et al. [17] and Gerber et al. [19] stated that sometimes cholangiocarcinoma may exhibit similar enhancement criteria in CT and MRI as hepatocellular carcinomas, so discrimination between cholangiocarcinomas and hepatocellular carcinoma can be difficult in 


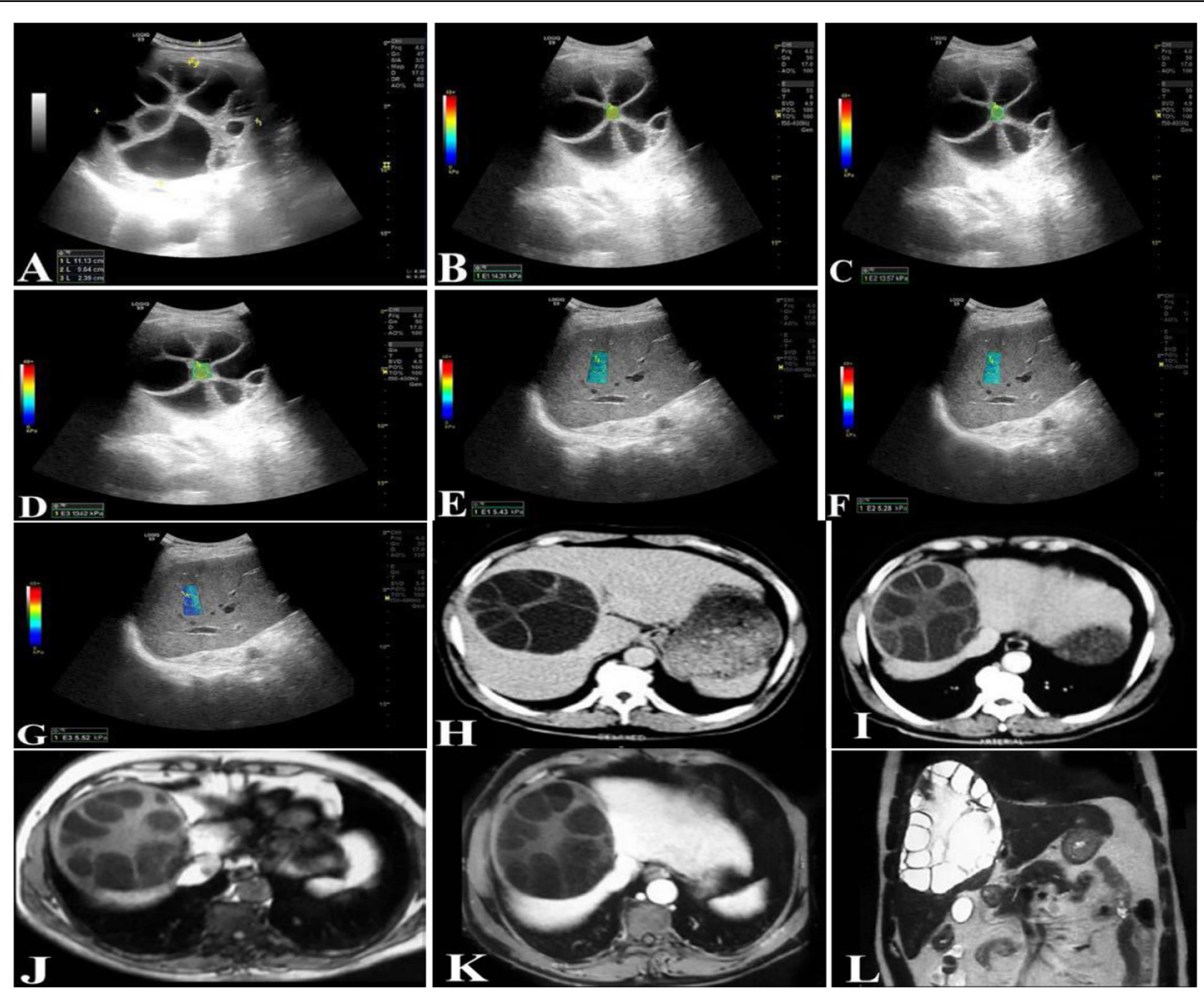

Fig. 3 Fifty-eight years old male patient presented with abdominal fullness. Imaging findings: grey scale B-mode Ultrasonography (a): normal sized liver with a well-defined anechoic focal lesion with septations inside seen occupying most of the right liver lobe measuring $11.1 \times 9.6 \mathrm{~cm}$ with $2.3 \mathrm{~cm}$ depth from the skin. $\varpi$ Color-coded shear wave sono-elastography: measurements are taken in the septations showed yellow green color $(\mathbf{b}, \mathbf{c}, \mathbf{d})$, while the liver parenchyma showed dark blue color $(\mathbf{e}, \mathbf{f}, \mathbf{g})$. $\mathbf{\omega}$ Shear wave sono-elastography stiffness values of the focal lesion: E1 $=14.31 \mathrm{kPa}(\mathbf{b}), \mathrm{E} 2=13.57 \mathrm{kPa}(\mathbf{c})$, and E3 $=13.42 \mathrm{kPa}(\mathbf{d})$. Calculated average stiffness value of the lesion $=13.76 \mathrm{kPa}$. $\emptyset$ Shear wave sonoelastography stiffness values of the parenchyma: $\mathrm{E} 1=5.43 \mathrm{kPa}(\mathbf{e}), \mathrm{E} 2=5.28 \mathrm{kPa}(\mathbf{f})$, and $\mathrm{E} 3=5.52 \mathrm{kPa}(\mathbf{g})$. Calculated average stiffness value of the parenchyma $=5.41 \mathrm{kPa}$. Lesion/parenchyma stiffness ratio $=2.54$. $\varpi$ Axial contrast enhanced CT study (non-contrast (h), post-contrast (i)): a large well-defined non-enhancing multilocular cystic lesion with multiple septae and daughter cysts. It is seen occupying most of the right liver lobe. ๘ Contrast enhanced MRI study (non-contrast axial T1 (j), post-contrast fat sat T1 WI (k), and non-contrast coronal T2 WI (I)): a large well-defined non-enhancing multilocular cystic lesion with multiple septae and daughter cysts. It is seen occupying most of the right liver lobe. It displays low SI on T1 WI, high SI on T2 WI images, and shows no enhancement on post-contrast T1WI. 6 Diagnosis: hydatid cyst

Table 5 Shear wave elastography median (min-max) stiffness values (kPa) of different categories of benign and malignant hepatic focal lesions, and the surrounding liver parenchyma

\begin{tabular}{|c|c|c|c|c|c|}
\hline \multirow[t]{2}{*}{ Variables } & \multirow[t]{2}{*}{$N$} & \multicolumn{2}{|c|}{ Median kPa stiffness value (min-max) } & \multirow[b]{2}{*}{ Lesion/parenchymal stiffness ratio median } & \multirow{2}{*}{$\begin{array}{l}{ }^{z_{p}} \\
\text { value }\end{array}$} \\
\hline & & Focal lesions & Liver parenchyma & & \\
\hline All lesions & 75 & $18.37(0.0-37.51)$ & $6.47(4.38-18.20)$ & & $<0.001^{*}$ \\
\hline Malignant lesions & 52 & $20.22(14.04-37.51)$ & $7.86(4.48-18.20)$ & $2.69(0.83-5.50)$ & $<0.001^{*}$ \\
\hline Hepatocellular carcinoma & $21(28 \%)$ & $17.6(15.3-20.5)$ & $13.2(9.6-18.20)$ & $1.37(0.83-1.93)$ & $<0.001^{*}$ \\
\hline Metastasis & $21(28 \%)$ & $25.5(21.9-28.9)$ & $5.7(4.5-13.6)$ & $4.2(2.1-5.5)$ & $<0.001^{*}$ \\
\hline Lymphoma & $6(8 \%)$ & $14.5(14.04-14.7)$ & $5.8(4.8-9.2)$ & $2.5(1.5-2.9)$ & $0.004^{*}$ \\
\hline Cholangiocarcinoma & $4(5.3 \%)$ & $35.9(35.3-37.5)$ & $7.9(7.3-12.6)$ & $4.6(2.8-4.98)$ & $0.021^{*}$ \\
\hline Benign lesions & 23 & $10.68(0.0-27.76)$ & $5.97(4.38-7.08)$ & $2.69(0.83-5.50)$ & $<0.001^{*}$ \\
\hline Hemangioma & $6(8 \%)$ & $10.5(9.04-11.02)$ & $5.84(4.8-7.08)$ & $1.66(1.6-2.39)$ & $0.004^{*}$ \\
\hline Focal nodular hyperplasia & $5(6.7 \%)$ & $26.7(25.1-27.8)$ & $6.64(5.50-6.74)$ & $4.18(3.9-4.82)$ & $0.009^{*}$ \\
\hline Simple cyst & $2(2.7 \%)$ & $0.00(0.0-0.0)$ & $6.08(5.3-6.86)$ & $0.00(0.0-0.0)$ & 0.102 \\
\hline Hydatid cyst & $3(4 \%)$ & $8.79(8.1-13.76)$ & $5.77(5.41-6.86)$ & $1.41(1.2-2.54)$ & $0.05^{*}$ \\
\hline Fatty infiltration & $4(5.3 \%)$ & $10.3(8.23-11.32)$ & $5.57(4.4-6.20)$ & $1.81(1.7-2.08)$ & $0.021^{*}$ \\
\hline Abscess & $3(4 \%)$ & $12.67(12.6-12.8)$ & $5.97(5.83-6.43)$ & $2.12(1.9-2.21)$ & $0.05^{*}$ \\
\hline
\end{tabular}




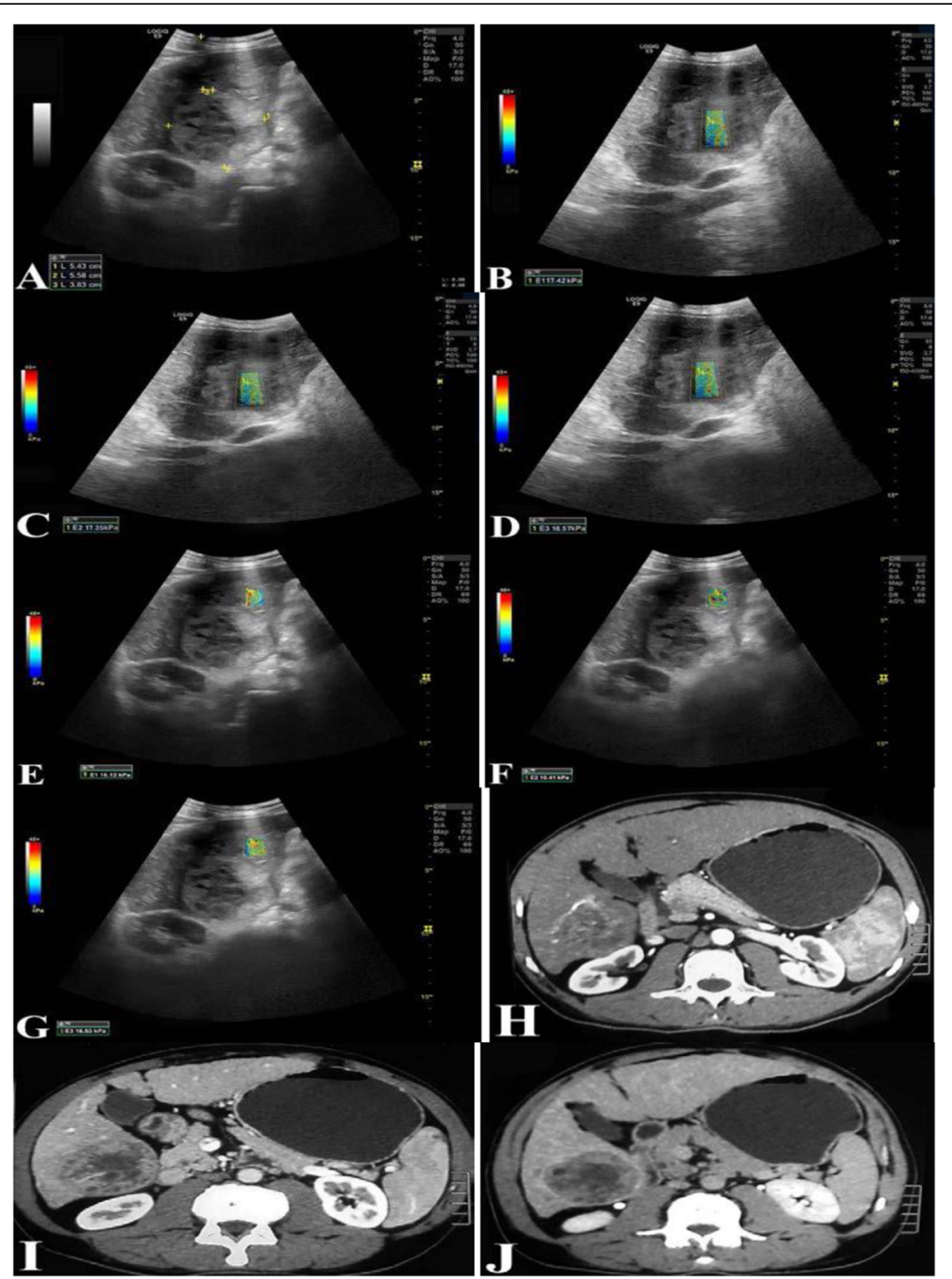

Fig. 4 Fifty-six years old male patient with chronic liver disease for follow-up abdominal ultrasound. Imaging findings: grey scale B-mode ultrasonography (a): normal sized cirrhotic liver with a well-defined hyperechoic focal lesion seen in segment VI measuring $5.4 \times 5.5 \mathrm{~cm}$ with 3.8 $\mathrm{cm}$ depth from the skin. $\boldsymbol{\varpi}$ Color-coded shear wave sono-elastography: the lesion $(\mathbf{b}, \mathbf{c}, \mathbf{d})$ and the parenchyma $(\mathbf{e}, \mathbf{f}, \mathbf{g})$ showed mixed color with red foci. $\varpi$ Shear wave sono-elastography stiffness values of the focal lesion: $\mathrm{E} 1=17.42 \mathrm{kPa}(\mathbf{b}), \mathrm{E} 2=17.35 \mathrm{kPa}(\mathbf{c})$, and E3 = $16.57 \mathrm{kPa}(\mathbf{d})$. Calculated average stiffness value of the lesion $=17.11 \mathrm{kPa}$. $\varpi$ Shear wave sono-elastography stiffness values of the parenchyma: $\mathrm{E} 1=16.12 \mathrm{kPa}$ $(\mathbf{e}), \mathrm{E} 2=16.41 \mathrm{kPa}(\mathbf{f})$, and $\mathrm{E} 3=16.53 \mathrm{kPa}(\mathbf{g})$. Calculated average stiffness value of the parenchyma $=16.35 \mathrm{kPa}$. Lesion/parenchyma stiffness ratio $=1.04$. $\varpi$ Axial contrast enhanced triphasic CT study (arterial (h), portal (i), delayed (j)): average size cirrhotic liver with a well-defined focal lesion seen in segment VI showing enhancement in the arterial phase and washout in portal and delayed phases. $\varpi$ Diagnosis:

hepatocellular carcinoma

these situations, and in Guibal et al. [17], there was a significant difference found between the elasticity of HCCs and CCCs (P 00.0004). These distinct differences in SWE could aid in the differentiation of HCCs and cholangiocarcinomas. Gerber et al. [19] concluded that the use of SWE can aid in the differentiation of HCCs and CCC as the median stiffness of CCC was 70.7, and there was a significant difference in stiffness compared to HCC median stiffness value (44.8).

The current study showed similar observations as cholangiocarcinoma median stiffness value (35.9) was much higher than that of hepatocellular carcinoma (17.6).

In this study, the elasticity values of metastases varied widely depending on the primary tumor type. Colorectal metastases (6 cases) median stiffness value (22.54 $\mathrm{kPa}$ ) was lower than breast cancer metastases (7 cases) median stiffness value $(26.25 \mathrm{kPa})$, this is in agreement with Guibal et al. [17] who reported that mean stiffness value of metastases from carcinoid tumors $(30.7 \mathrm{kPa})$ was higher than metastases from gastro-intestinal tract adenocarcinomas $(21.8 \mathrm{kPa})$. 


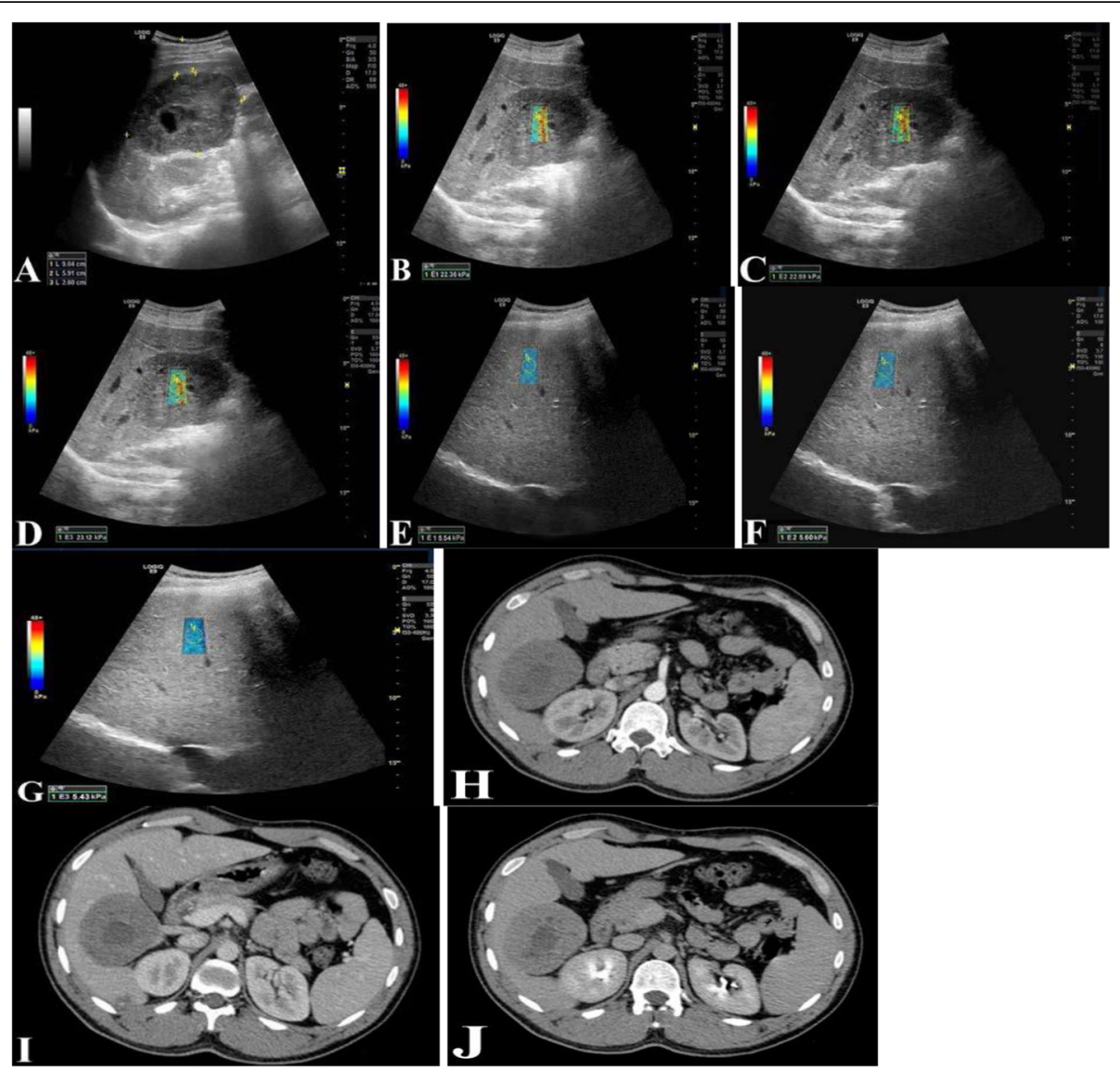

Fig. 5 Forty-four years old female patient with intestinal GIST seeking for metastatic work up. Imaging Findings: grey scale B-mode ultrasonography (a): normal sized liver with a well-defined hypoechoic focal lesion seen in segment VI measuring $9 \times 5.9 \mathrm{~cm}$ with $2.6 \mathrm{~cm}$ depth from the skin. $\boldsymbol{\varpi}$ Color-coded shear wave sono-elastography: the lesion showed mixed color with red foci (b, c, d), while the liver parenchyma showed dark blue color $(\mathbf{e}, \mathbf{f}, \mathbf{g})$. $\varpi$ Shear wave sono-elastography stiffness values of the focal lesion: E1 = $22.36 \mathrm{kPa}(\mathbf{b})$, E2 = $22.59 \mathrm{kPa}(\mathbf{c})$, and E3 $=23.12 \mathrm{kPa}$ (d). Calculated average stiffness value of the lesion $=22.69 \mathrm{kPa}$. $\varpi$ Shear wave sono-elastography stiffness values of the parenchyma: $\mathrm{E} 1=5.54 \mathrm{kPa}(\mathbf{e}), \mathrm{E} 2=5.60 \mathrm{kPa}(\mathbf{f})$, and E3 $=5.43 \mathrm{kPa}(\mathbf{g})$. Calculated average stiffness value of the parenchyma $=5.52 \mathrm{kPa}$. Lesion/parenchyma stiffness ratio $=4.11 . \omega$ Axial contrast enhanced triphasic CT study (arterial (h), portal (i), delayed (j) phases): normal size liver with a well-defined focal lesion seen in segment VI showed faint enhancement with central necrotic area. $\varpi$ Pathology: metastasis from GIST. $\varpi$ Diagnosis: metastasis from GIST

Lymphoma showed elevated median stiffness value $14.5 \mathrm{kPa}$ comparing to the surrounding liver parenchyma $5.8 \mathrm{kPa}$, and this matches with Park et al. [21], as lymphoma mean stiffness value was $31.9 \mathrm{kPa}$, while the surrounding liver parenchyma mean stiffness value was $8.7 \mathrm{kPa}$.

The lesion to parenchyma stiffness ratio may be of a clinical value in patient with liver fibrosis as, in the current study: HCC lesion/parenchyma stiffness ratio was (1.37) lower than cholangiocarcinoma lesion/parenchyma stiffness ratio (4.6), and also lower than metastasis lesion/parenchyma stiffness ratio (4.2). This was attributed to fibrosis in the surrounding hepatic parenchyma. These results coping with Park et al. [21] and De-Wall et al. [29] who reported that regarding stiffness ratio of FLL to adjacent liver parenchyma, HCC showed lower ratio than all of other malignant FLLs except combined HCC-CCC and showed similar ratio value compared with benign FLLs. This may be attributed to the liver cirrhosis background in most patients with HCC.

In this study, the median benign focal lesion stiffness value $(10.68 \mathrm{kPa})$ was significantly lower than that of malignant focal lesions $(20.22 \mathrm{kPa})$ with a statistical significance $P$ value $<0.001$. This matches with Guibal et al. [17] who reported that the mean value for the benign focal lesions was $18.53 \pm 13.5 \mathrm{kPa}$ and for the malignant focal lesions was $26.9 \pm 18.8 \mathrm{kPa}$ with statistical significance $P$ value $=00.01$, and matches also with Park et al. [21] who reported that the malignant focal lesion mean stiffness value was $60.41 \pm 47.81 \mathrm{kPa}$, while that of benign focal lesions was $22.05 \pm 17.24 \mathrm{kPa}$ with statistical significance $P$ value $=0.0001$. Also, this is in agreement with Gerber et al. [19] results who reported that the 


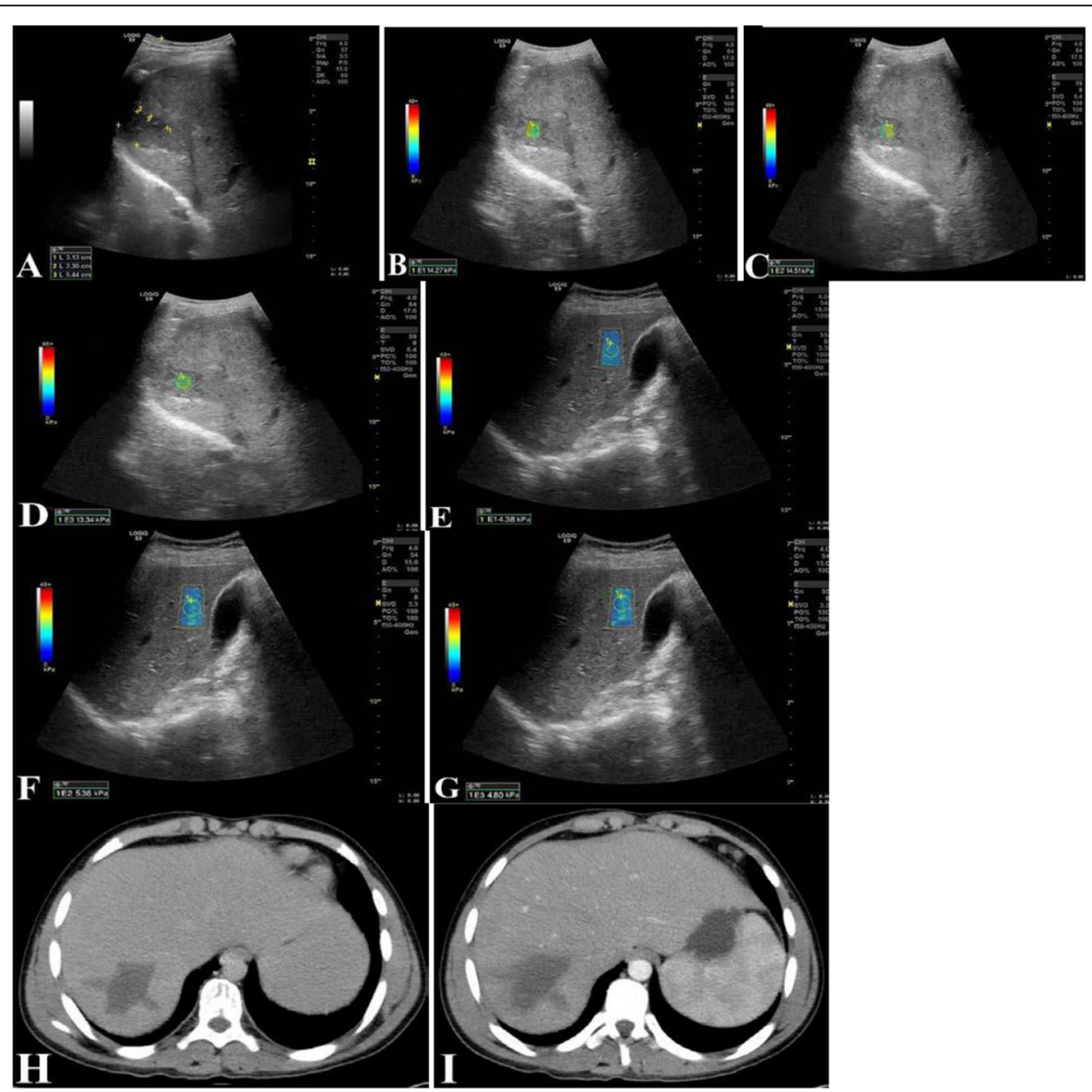

Fig. 6 Thirty-seven years old male patient with non-Hodgkin lymphoma seeking for abdominal ultrasound to exclude abdominal lymphomatous infiltration. Imaging findings: grey scale B-mode ultrasonography (a): normal sized liver with an ill-defined hypoechoic focal lesion seen in segment VII measuring $3.1 \times 2.3 \mathrm{~cm}$ with $5.4 \mathrm{~cm}$ depth from the skin. $\boldsymbol{~}$ Color-coded shear wave sono-elastography: the lesion showed yellow green color $(\mathbf{b}, \mathbf{c}, \mathbf{d})$, while the liver parenchyma showed dark blue color $(\mathbf{e}, \mathbf{f}, \mathbf{g})$. $\boldsymbol{\varpi}$ Shear wave sono-elastography stiffness values of the focal lesion: $\mathrm{E} 1=14.27 \mathrm{kPa}(\mathbf{b}), \mathrm{E} 2=14.51 \mathrm{kPa}(\mathbf{c})$, and E3 = $13.34 \mathrm{kPa}(\mathbf{d})$. Calculated average stiffness value of the lesion $=14.04 \mathrm{kPa}$. $\mathbf{D}$ Shear wave sono-elastography stiffness values of the parenchyma $(\mathbf{e}, \mathbf{f}, \mathbf{g})$ : $\mathrm{E} 1=4.38 \mathrm{kPa}(\mathbf{e}), \mathrm{E} 2=5.36 \mathrm{kPa}(\mathbf{f})$, and E3 $=4.80 \mathrm{kPa}$ (g). Calculated average stiffness value of the parenchyma $=4.84 \mathrm{kPa}$. Lesion/parenchyma stiffness ratio $=2.90$. $\varpi$ Axial contrast enhanced CT study (non-contrast (h), post contrast (i)): normal size liver with a well-defined hypodense focal lesion seen in segment VIl showed faint peripheral enhancement. $\boldsymbol{D}$ Pathology: lymphoma. $\varpi$ Diagnosis: hepatic lymphomatous infiltration

benign focal lesion median stiffness value was 16.4 and the malignant focal lesion median stiffness value was 36 with statistically significant $P$ value $<0.0001$.

These studies of Guibal et al. [17], Gerber et al. [19], Park et al. [21], Brunel et al. [30], Ferraioli et al. [31], and Xie et al. [32] added that the main role of the technique was to differentiate between adenoma and FNH in benign category and between HCC and cholangiocarcinoma in malignant category as the usual radiological imaging modalities may have overlap and conflict in diagnosis between some cases of these categories.

The results of the current study showed that cholangiocarcinoma median stiffness value (35.9) was much higher than that of hepatocellular carcinoma (17.6). Unfortunately, the current study did not include adenoma cases to differentiate between it and FNH, unlike Guibal et al. [17] study results that included (10 adenoma cases) with mean stiffness value $9.4 \pm 4.3 \mathrm{kPa}$ and $(16 \mathrm{FNH}$ cases) with mean stiffness value $33 \pm-14.7 \mathrm{kPa}$, and Brunel et al. [30] study that included (57 FNH and 19 adenoma) with mean elasticity value $46.99 \pm 31.15 \mathrm{kPa}$ for $\mathrm{FNH}$ and $12.08 \pm 10.68 \mathrm{kPa}$ for adenoma.

In this study, the receiver operating characteristic (ROC) curve of SWE stiffness values for differentiation of benign from malignant hepatic focal lesions had AUC $=0.834$ and using cutoff value $14.165 \mathrm{kPa}$, yielding 98.1\% sensitivity, $78.3 \%$ specificity, and 92\% accuracy; however, in the study of Park et al. [21], the (ROC) curve showed that using a cutoff value of $30.8 \mathrm{kPa}$ with AUC 0.79 , yielding $70.6 \%$ sensitivity and $82.4 \%$ specificity. 


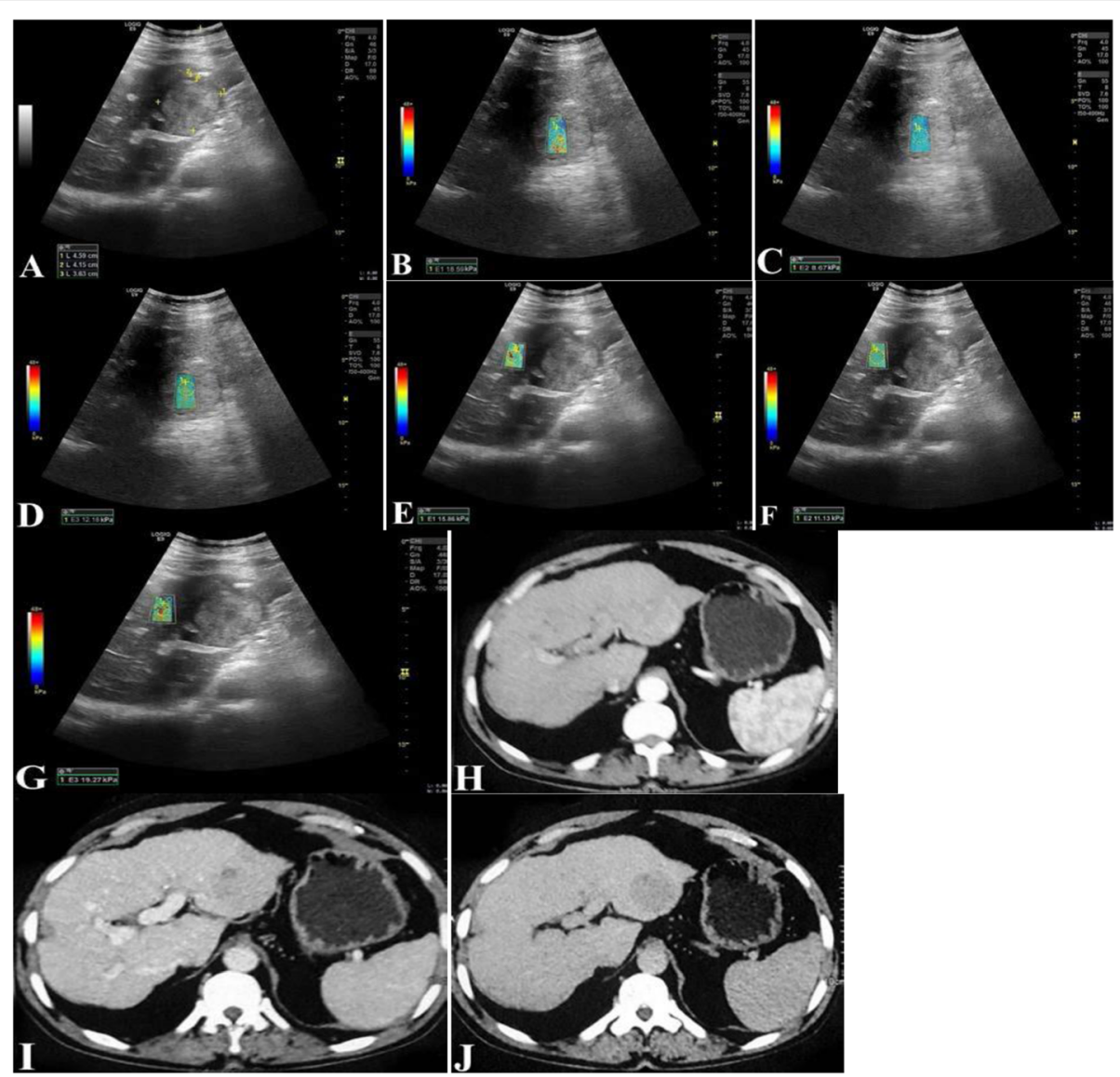

Fig. 7 (example of left lobe focal lesion): 55 years old male patient with chronic liver disease under follow up abdominal ultrasound. Imaging findings: grey scale B-mode ultrasonography (a): shrunken cirrhotic liver with a well-defined hyperechoic focal lesion seen in left lobe measuring $4.5 \times 4.1 \mathrm{~cm}$ with $3.6 \mathrm{~cm}$ depth from the skin. $\varpi$ Color-coded shear wave sono-elastography: the lesion (b, $\mathbf{c}, \mathbf{d})$ and parenchyma (e, f, g) showed variable colors in the three acquisitions. $\varpi$ Shear wave sono-elastography stiffness values of the focal lesion: the lesion showed variable stiffness values in the three acquisitions. $\mathrm{E} 1=18.59 \mathrm{kPa}(\mathbf{b}), \mathrm{E} 2=8.67 \mathrm{kPa}(\mathbf{c})$, and $\mathrm{E} 3=12.18 \mathrm{kPa}(\mathbf{d})$. Calculated average stiffness value of the three acquisitions $=13.14 \mathrm{kPa}$. $\varpi$ Shear wave sono-elastography stiffness values of the parenchyma: the parenchyma showed variable stiffness values in the three acquisitions. E1 $=15.86 \mathrm{kPa}(\mathbf{e}), \mathrm{E} 2=11.13 \mathrm{kPa}(\mathbf{f})$, and E3 $=19.27 \mathrm{kPa}(\mathbf{g})$. Calculated average stiffness value of the three acquisitions $=$ $15.42 \mathrm{kPa}$. Lesion/parenchyma stiffness ratio $=0.89$. $\varpi$ Axial contrast enhanced triphasic CT study (arterial $(\mathbf{h})$, portal (i), delayed (j)): shrunken cirrhotic liver with a well-defined focal lesion seen in left lobe showed enhancement in the arterial and portal phases with washout in delayed phase. $\varpi$ Diagnosis: left lobe HCC

This difference in sensitivity may be attributed that there was a sample size difference between the current study (75 lesions) and Park et al. [21] study (136 lesions).

\section{The current study had some limitations}

1-Relatively small sample size (75 cases)

2-Failure of SWE acquisitions in left liver lobe focal lesions because of excess tissue movement due to cardiac and respiratory motion and failure in right liver lobe focal lesions with depth greater than $6 \mathrm{~cm}$ from the skin because of the lesion location beyond the penetration limits of shear waves. These are the same limitations encountered in conventional ultrasound as mentioned by Guibal et al. [17] and Park et al. [21]. This point needs further assessment.

3-This study is missing some categories (e.g., adenoma and focal fatty sparing) or containing small number of some other categories (e.g., hydatid cyst (3 cases),

Table 6 Diagnostic accuracy of SWE stiffness values for differentiation of benign from malignant hepatic focal lesions based on ROC curve

\begin{tabular}{lllllllll}
\hline AUC & $95 \% \mathrm{Cl}$ & $P$ value & Cutoff & Sensitivity & Specificity & PPV & NPV & Accuracy \\
\hline 0.834 & $0.71-0.97$ & $<0.001$ & 14.165 & $98.1 \%$ & 78.3 & 91.1 & 94.7 & $92 \%$ \\
\hline
\end{tabular}

AUC area under the curve, $\mathrm{Cl}$ confidence interval, $P P V$ positive predictive value, NPV negative predictive value

$\mathrm{ROC}$ curve for diagnostic accuracy of SWE stiffness values for differentiation of benign from malignant hepatic focal lesions 
abscess (3), focal fatty infiltration (4), cholangiocarcinoma (4), and FNH (5)).

\section{Recommendations}

Further large scale research is needed to assess the use of shear wave sono-elastography to help in differentiation between malignant and benign hepatic focal lesions.

\section{Conclusion}

Although SWE is a recent technique, which needs more evaluation and several researches are needed to assess its use as an alternative to liver biopsy and other radiological imaging techniques, its initial results are promising as described in the current study. Shear wave elastography is a useful technique with high sensitivity and accuracy in differentiating benign form malignant liver focal lesions as the results demonstrated that malignant lesion stiffness values were higher comparable to the benign lesions values.

The technique shows promising results in individual characterization of some malignant (HCC and CCC) and benign hepatic focal lesion (FNH from other benign lesions) (for further research).

\section{Abbreviations}

FLLs: Focal liver lesions; MRI: Magnetic resonance imaging; CT: Computed tomography; PET: Positron emission tomography; SWE: Shear wave sonoelastography; N: Number; CE-CT: Contrast enhanced computed tomography; CE-MRI: Contrast enhanced magnetic resonance imaging; ROI: Region of interest; CT: Computed tomography; MRI: Magnetic resonance imaging; SPSS: Statistical package for social science; SD: Standard deviation; ROC curve: Receiver operator characteristics curve; AUC: Area under the curve; $P$ value: Probability value; GIST: Gatstro-intestinal stromal tumor; FNH: Focal nodular hyperplasia; HCC: Hepatocellular carcinoma;

CCC: Cholangiocarcinoma; e.g.: For example

\section{Acknowledgements}

To technicians at radiology department who help in examination of patients

\section{Authors' contributions}

M.A.L.: writing of the manuscript, final revision of data, statistical tables, and radiological images, and finalization of the research manuscript. N. F.: idea of the research, supervision of radiological examinations of patients, and revision of data. O.A.SH.: helping in radiological examination of patients and revision of data. A.A.R.: collecting of data, helping in writing of the manuscript, and helping in radiological examination of patients (under supervision). All authors read and approved the final manuscript.

\section{Funding}

Not applicable (no funding).

\section{Availability of data and materials}

Authors can confirm that all relevant data are included in the article and/or its supplementary information files.

\section{Ethics approval and consent to participate}

This study was approved by the Mansoura Faculty of Medicine-Institutional Research Board (MFM-IRB), and written informed consent to participate was obtained from all patients. Ethics committee reference number (Code No. MS/16.09.16).

\section{Consent for publication}

All patients included in this research gave written informed consent to publish the data contained within this study.

\section{Competing interests}

The authors declare that they have no competing interests.

Received: 8 January 2020 Accepted: 15 April 2020

Published online: 24 April 2020

\section{References}

1. Bosch FX, Ribes J, Cléries R et al (2005) Epidemiology of hepatocellular carcinoma. Clin Liver Dis 9(2):191-211

2. Cogley JR, Miller FH (2014) MR imaging of benign focal liver lesions. Radiol Clin N Am 52:657-682

3. Nault JC, Bioulac-Sage P, Zucman-Rossi J (2013) Hepatocellular benign tumors-from molecular classification to personalized clinical care. Gastroenterology 144:888-902

4. Bastati N, Feier D, Wibmer A et al (2014) Noninvasive differentiation of simple steatosis and steatohepatitis by using gadoxetic acid-enhanced MR imaging in patients with nonalcoholic fatty liver disease: a proof-of-concept study. Radiology 271:739-747

5. Smith-Bindman R, Miglioretti DL, Johnson E et al (2012) Use of diagnostic imaging studies and associated radiation exposure for patients enrolled in large integrated health care systems, 1996-2010. JAMA 9:307-2400

6. Tian WS, Lin MX, Zhou LY et al (2016) Maximum value measured by 2-D shear wave elastography helps in differentiating malignancy from benign focal liver lesions. Ultrasound Med Biol 42(9):2156-2166

7. Bedossa P, Dargere D, Paradis V (2003) Sampling variability of liver fibrosis in chronic hepatitis C. Hepatology 38:1449-1457

8. Atwell TD, Smith RL, Hesley GK et al (2010) Incidence of bleeding after 15,181 percutaneous biopsies and the role of aspirin. AJR Am J Roentgenol 194:784-789

9. Gutiérrez MV, Enciso RJ (2017) Liver elastography: what it is, how it is done, and how it is interpreted. Radiologia. 60(3):183-189

10. Fang C, Jaffer OS, Yusuf GT et al (2018) Reducing the number of measurements in liver point shear-wave elastography: factors that influence the number and reliability of measurements in assessment of liver fibrosis in clinical practice. Radiol 287(3):844-852

11. Liana G, Speranta I, Cristian G (2008) Real-time sonoelastography: a new application in the field of liver disease. J Gastrointestin Liver Dis 17(4): 469-474

12. Varbobitis IC, Siakavellas SI, Koutsounas IS et al (2016) Reliability and applicability of two-dimensional shear-wave elastography for the evaluation of liver stiffness. Eur J GastroenterolHepatol 10:1204-1209

13. Sebag F, Vaillant-Lombard J, Berbis J et al (2010) Shear wave elastography: a new ultrasound imaging mode for the differential diagnosis of benign and malignant thyroid nodules. J ClinEndocrinolMetab 95:5281-5288

14. Jeong WK, Lim HK, Lee HK et al (2014) Principles and clinical application of ultrasound elastography for diffuse liver disease. Ultrasonography 33(3):149-160

15. Ferraioli G, Parekh P, Levitov AB et al (2014) Shear wave elastography for evaluation of liver fibrosis. J Ultrasound Med 33(2):197-203

16. Samir AE, Dhyani M, Vij A et al (2015) Shear wave elastography for the estimation of liver fibrosis in chronic liver disease: determining accuracy and ideal site for measurement. Radiology 274:888-896

17. Guibal A, Boularan C, Bruce M et al (2013) Evaluation of shear wave elastography for the characterization of focal liver lesions on ultrasound. EurRadiol. 23(4):1138-1149

18. Qiang Lu, Changli Lu, Jiawu LI et al (2015) Hepatocellular carcinoma: stiffness value and ratio to discriminate malignant from benign focal liver lesions. Radiology 275(3):880-888

19. Gerber L, Fitting D, Srikantharajah K et al (2017) Evaluation of 2D- shear wave elastography for characterization of focal liver lesions. J Gastrointestin Liver Dis 3:283-290

20. Choong KL, Wong $\mathrm{YH}$, Yeong $\mathrm{CH}$ et al (2017) Elasticity characterization of liver cancers using shear wave ultrasound elastography: comparison between hepatocellular carcinoma and liver metastasis. Journal of Diagnostic Medical Sonography 33(6):481-488 
21. Park HS, Kim YJ, Yu MH et al (2015) Shear wave elastography of focal liver lesion: intraobserver reproducibility and elasticity characterization. Ultrasound Q 31:262-271

22. Kim JE, Lee JY, Bae KS et al (2013) Acoustic radiation force impulse elastography for focal hepatic tumors: usefulness for differentiating hemangiomas from malignant tumors. Korean J Radiol 14(5):743-753

23. Yu H, Wilson SR (2011) Differentiation of benign from malignant liver masses with acoustic radiation force impulse technique. Ultrasound Q 27(4): 217-223

24. Sirica AE, Campbell DJ, Dumur Cl (2011) Cancer-associated fibroblasts in intrahepatic cholangiocarcinoma. Curr Opin Gastroenterol 27:276-284

25. Okamoto K, Tajima H, Ohta T et al (2010) Angiotensin II induces tumor progression and fibrosis in intrahepatic cholangiocarcinoma through an interaction with hepatic stellate cells. Int J Oncol 37:1251-1259

26. Heide R, Strobel D, Bernatik T et al (2010) Characterization of focal liver lesions (FLL) with acoustic radiation force impulse (ARFI) elastometry. Ultraschall Med 31:405-409

27. Frulio N, Laumonier H, Carteret T et al (2013) Evaluation of liver tumors using acoustic radiation force impulse elastography and correlation with histologic data. J Ultrasound Med 32(1):121-130

28. Gallotti A, D'Onofrio M, Romanini L et al (2012) Acoustic radiation force impulse (ARFI) ultrasound imaging of solid focal liver lesions. Eur J Radiol 81(3):451-455

29. De-Wall RJ, Bharat S, Varghese T et al (2012) Characterizing the compression-dependent viscoelastic properties of human hepatic pathologies using dynamic compression testing. Phys Med Biol 57(8):22732286

30. Brunel T, Guibal A, Boularan C et al (2015) Focal nodular hyperplasia and hepatocellular adenoma: the value of shear wave elastography for differential diagnosis. Eur J Radiol 84(11):2059-2064

31. Ferraioli G, Wai-sun IW, Castera L et al (2018) Liver ultrasound elastography: an update to the world federation for ultrasound in medicine and biology guidelines and recommendations. Ultrasound Med Biol:1-22

32. Xie LT, Yan CH, Zhao QY et al (2018) Quantitative and non-invasive assessment of chronic liver diseases using two-dimensional shear wave elastography. World J Gastroenterol 24(9):957-970

\section{Publisher's Note}

Springer Nature remains neutral with regard to jurisdictional claims in published maps and institutional affiliations.

\section{Submit your manuscript to a SpringerOpen ${ }^{\circ}$ journal and benefit from:}

- Convenient online submission

- Rigorous peer review

- Open access: articles freely available online

High visibility within the field

- Retaining the copyright to your article

Submit your next manuscript at $\boldsymbol{\nabla}$ springeropen.com 